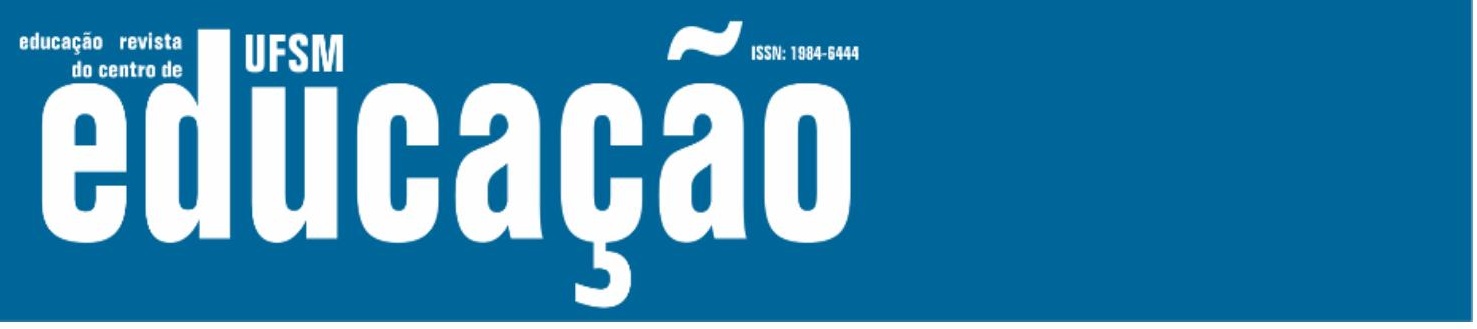

ISSN: 1984-6444 | http://dx.doi.org/10.5902/1984644438667

\title{
Juventudes rurais e educação na produção do conhecimento das pós-graduações das áreas de ciências humanas e sociais aplicadas do nordeste brasileiro
}

Rural youth and education in the production of postgraduate knowledge in the areas of applied human and social sciences in the Brazilian

Northeast

Samuel Pires Melo

Professor doutor na Universidade Federal do Piauí, Campus Ministro Reis Velloso. Parnaíba, Piauí, Brasil.

samuelmelo@ufpi.edu.br - http://orcid.org/0000-0003-0655-2917

Thais Maria Santos Macedo

Graduanda em Pedagogia pela Universidade Federal do Piauí, Campus Ministro Reis Velloso. Parnaíba, Piauí, Brasil.

thaismariap@hotmail.com - https://orcid.org/0000-0002-4461-7470

Isabela Maria do Nascimento Chaves

Graduanda em Pedagogia pela Universidade Federal do Piauí, Campus Ministro Reis Velloso. Parnaíba, Piauí, Brasil.

isabelamaria39@gmail.com - https://orcid.org/0000-0003-4286-1856

Recebido em 21 de junho de 2019

Aprovado em 24 de agosto de 2020

Publicado em 31 de janeiro de 2021

\section{RESUMO}

O artigo tem como objetivo discutir, sob os processos educacionais, as produções do conhecimento sobre as juventudes rurais, particularmente entre os anos de 2007 e 2016. Estes recortes de pesquisa procuram situar o processo social de um rumo científico ligado à produção de pesquisadores dos programas de pós-graduação do Nordeste do Brasil das áreas de ciências humanas e sociais aplicadas, especificamente, as características que possibilitam mostrar o perfil dos autores com a temática, bem como as estratégias utilizadas, teórico-metodologicamente, na compreensão desse grupo social, em seu vínculo com a educação. Para isso, buscou-se realizar um estudo do tipo Estado da Arte, sob a abordagem qualitativa, com instrumentos de coleta - diário de campo e questionário aberto; e de interpretação - a técnica da Análise de Conteúdo de Bardin e os softwares IRAMUREQ e EXCEL. Na trajetória dos autores das teses e dissertações, eles têm se dedicado a trabalhar na pesquisa sobre o tema de forma diversa ao longo de sua carreira, mas pouco às atividades de ensino e extensão. As temáticas dos estudos 


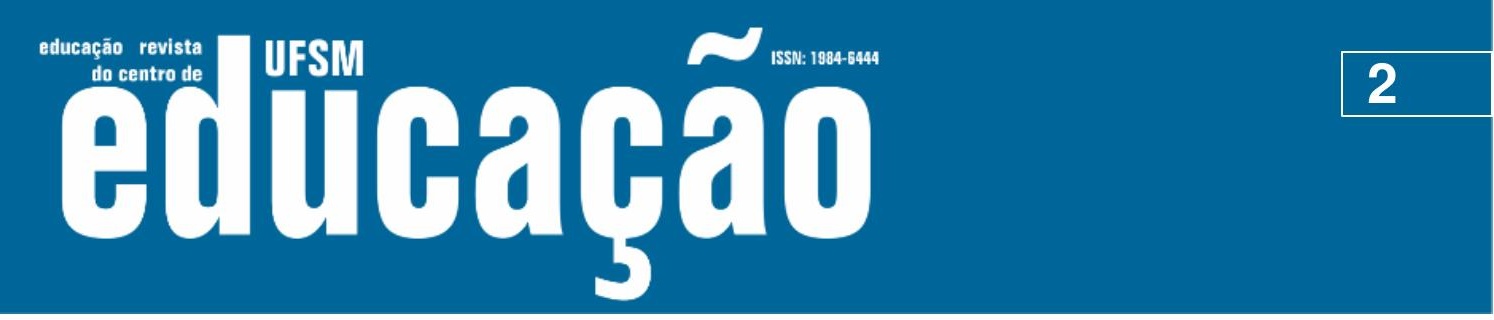

ISSN: 1984-6444 | http://dx.doi.org/10.5902/1984644438667

revelam singularidades, mas também linhas mestras que possibilitam situar teóricometodologicamente, desde correntes que ultrapassam às estrutural-funcionalistas, fenomenológicas e pós-estruturalistas. Portanto, observou-se a procedência autoral dos trabalhos acadêmicos, com discussões que têm trazido novos caminhos para a produção dos Programas de Pós-Graduação, possibilitando repensar os campos de conhecimentos das áreas de Ciências Humanas e Sociais Aplicadas.

Palavras-chave: Juventudes; Ruralidades; Educação.

\section{ABSTRACT}

The article aims to discuss, under educational processes, the production of knowledge about rural youth, particularly in the years 2007 to 2016 . These research cuts seek to situate the social process of a scientific course linked to the production of researchers of the programs of graduate studies in Northeast Brazil from the areas of applied human and social sciences, specifically the characteristics that make it possible to show the profile of the authors with the theme, as well as the strategies used theoretically and methodologically in the understanding of this social group in its link with education. In order to do so, the study sought to carry out a state - of - the art study under the qualitative approach, with field - collection and questionnaire open instruments; and interpretation - the Bardin Content Analysis technique and the IRAMUREQ and EXCEL softwares. In the trajectory of the authors of theses and dissertations, they have been dedicated to work on research on the subject in a different way throughout their career, but little to teaching and extension activities. The themes of the studies reveal singularities, but also master lines that allow to situate theoretically-methodologically, which exceed the structural-functionalists currents, phenomenological and post-structuralist ones. Therefore, it was observed the authorial origin of the academic works, with discussions that have brought new paths for the production of the Graduate Programs, allowing to rethink the fields of knowledge of the Humanities and Applied Social Sciences areas.

Keywords: Youths; Ruralidades; Education.

\section{Introdução}

Esta pesquisa tem como objetivo discutir, sob os processos educacionais, a produção do conhecimento das juventudes rurais, particularmente entre os anos de 2007 e 2016. Estes recortes de pesquisa, que dizem respeito principalmente aos segmentos educacionais e das juventudes rurais, procuram compreender o processo social de um rumo científico ligado à produção do conhecimento de programas de 


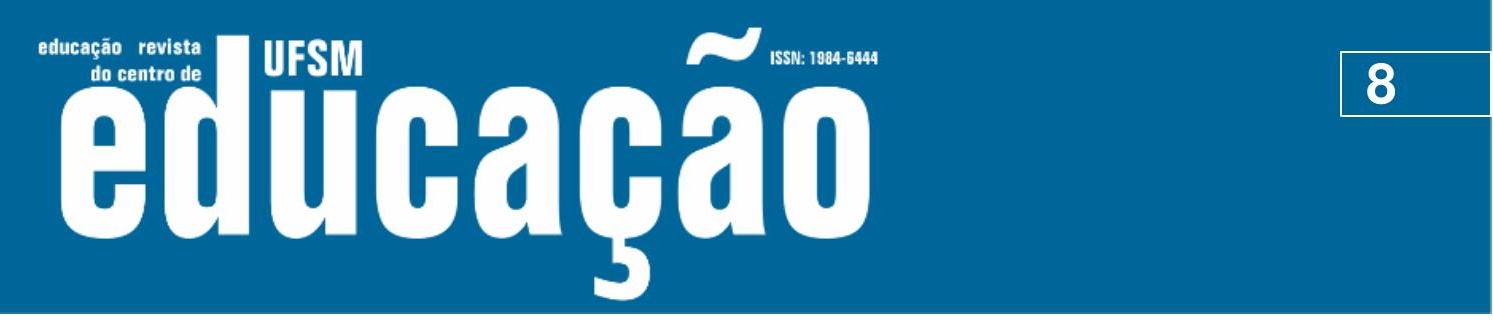

ISSN: 1984-6444 | http://dx.doi.org/10.5902/1984644438667

análise estatística de dados referentes ao perfil dos autores das teses e dissertações com as temáticas juventudes, ruralidades e educação. Para isso, buscou-se o currículo lattes de cada um dos autores das teses e dissertações, selecionando os seguintes pontos que envolviam a temática: ano em que passou a trabalhar com a temática; quantidade de trabalhos publicados, eventos que participou, atividade de ensino e extensão que realizou envolvendo a temática.

\section{Juventudes rurais e educação na pós-graduação do nordeste brasileiro}

Ao identificar a produção dos programas de pós-graduação do nordeste brasileiro, nas áreas das ciências humanas e sociais aplicadas, buscou-se também analisá-la, categorizá-la e revelar os múltiplos enfoques e perspectivas, tanto em termos da trajetória dos autores pesquisadores nas temáticas de juventudes rurais e educação, quanto às perspectivas teórico-metodológicas das produções textuais dessas dissertações e teses.

\section{Trajetórias de pesquisadores com as temáticas juventudes rurais e educação}

A trajetória dos autores das teses e dissertações pesquisadas mostram a relação autoral das atividades acadêmico-científicos com as temáticas da juventude rural e educação. Este mapeamento possibilitou dizer que muitos dos pesquisadores têm se dedicado a trabalhar no tema sobre juventude rural ao longo de sua carreira, além de dar visibilidade aos seus grupos de estudos e às atividades de ensino e extensão. Desse modo, os dados permitem compreender a autoridade desses autores no campo acadêmico (BOURDIEU, 1989).

Um primeiro ponto a ser destacado na trajetória desses pesquisadores, diz respeito ao gênero. Observou-se, tabela 1 , que um pouco mais da metade $(57,7 \%)$ das autoras dos trabalhos das teses e dissertações é do sexo feminino. Esse percentual mostra o crescimento no número de mulheres pesquisadoras que desenvolvem seus trabalhos na linha de juventude, educação e ruralidade. Leta (2003) salienta a falta de informações sistemáticas sobre a formação e o perfil dos 


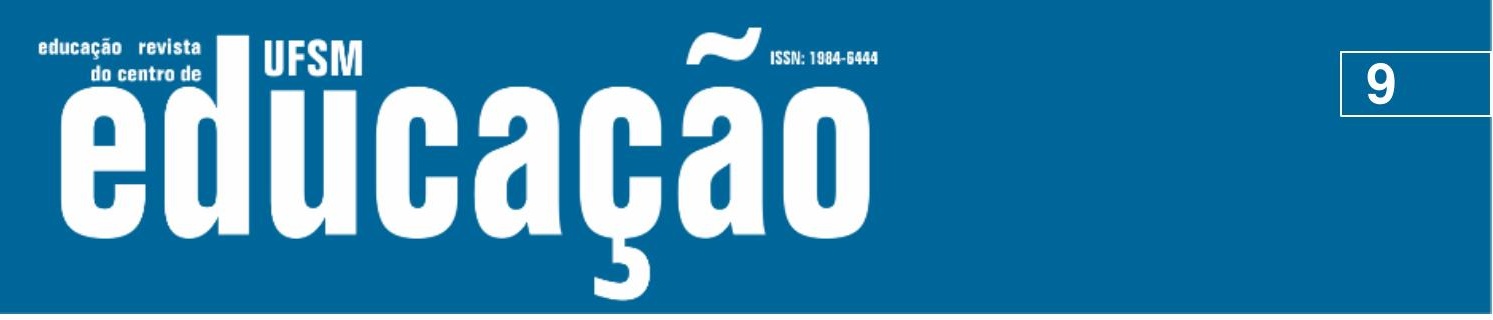

ISSN: 1984-6444 | http://dx.doi.org/10.5902/1984644438667

recursos humanos na educação superior e na ciência brasileira, mas segundo ela:

Apesar da recente institucionalização da ciência brasileira, foi também nos anos de 1980 e 1990 que as mulheres brasileiras aumentaram sua participação no setor [...] Mas fato é que, aos olhos, principalmente, dos mais "seniores", é evidente a mudança na universidade brasileira no que diz respeito à freqüência de mulheres: diferente de algumas poucas décadas atrás, elas hoje são a maioria em boa parte dos cursos de graduação e de pós-graduação do país (LETA, 2003, p.273).

É importante salientar a relação entre a maior participação das mulheres e a institucionalização da ciência nas décadas de 80 e 90 (LETA, 2003). Isso para dizer que com o passar dos anos o número de mulheres fazendo ciência no Brasil têm aumentado significativamente. Nesse crescimento, evidencia-se na análise deste artigo uma concentração das teses e dissertações produzidas por mulheres entre o ano de 2014 e 2016, embora a delimitação deste estudo seja apenas de 2007 a 2016. Especificamente, no período de 2014 e 2016 foram produzidos praticamente a metade $(49,4 \%)$ dos trabalhos, seguido do intervalo entre 2011 e 2013 com $34,8 \%$ e 2007 a 2009 com 15,7\%. (ver tabela 1).

Tabela 1 - Trajetória dos pesquisadores das teses e dissertações dos Programas de Pós-graduação do Nordeste do Brasil

\begin{tabular}{c|c}
\hline VARIÁVEIS & $\mathbf{n}(\%)$ \\
Sexo & $11(42,3)$ \\
Masculino & $15(57,7)$ \\
Feminino & $\mathbf{2 6 ( 1 0 0 )}$ \\
Total & \\
\hline Ano de defesa das Teses e Dissertações & $4(15,7)$ \\
$2007-2009$ & $9(34,8)$ \\
$2011-2013$ & $13(49,4)$ \\
$2014-2016$ & $\mathbf{2 6}(100)$ \\
Total & \\
\hline Áreas dos Programas de Pós-Graduação & $4(15,7)$ \\
Ciências humanas e sociais & $22(84,3)$ \\
Ciências sociais aplicadas & $\mathbf{2 6}(100)$ \\
Total & \\
Nível dos Programas de Pós-Graduação & $23(88,5)$ \\
Mestrado & $3(11,5)$ \\
Doutorado & $\mathbf{2 6 ( 1 0 0 )}$ \\
Total &
\end{tabular}




\section{त्ञ Hsm

ISSN: 1984-6444 | http://dx.doi.org/10.5902/1984644438667

Continuação Tabela 1 - Trajetória dos pesquisadores das teses e dissertações dos Programas de Pós-graduação do Nordeste do Brasil

\begin{tabular}{|c|c|}
\hline $\begin{array}{l}\text { Ano com início de publicações sobre o tema } \\
2004 \\
2005 \\
2006 \\
2007 \\
2008 \\
2009 \\
2010 \\
2011 \\
2013 \\
\text { Total }\end{array}$ & $\begin{array}{c}1(3,8) \\
2(7,7) \\
1(3,8) \\
2(7,7) \\
1(3,8) \\
4(15,4) \\
8(30,9) \\
6(23,1) \\
1(3,8) \\
26(100)\end{array}$ \\
\hline $\begin{array}{l}\text { Quantidade de trabalhos publicados sobre o tema } \\
0-10 \\
11-53 \\
\text { Total }\end{array}$ & $\begin{array}{c}17(65,4) \\
9(34,6) \\
26(100)\end{array}$ \\
\hline $\begin{array}{c}\text { Eventos que participou envolvendo o tema } \\
0-6 \\
12-27 \\
\text { Total }\end{array}$ & $\begin{array}{l}19(73,1) \\
7(26,9) \\
26(100)\end{array}$ \\
\hline $\begin{array}{c}\text { Atividade de Extensão realizada envolvendo o tema } \\
0 \\
1 \\
2 \\
3 \\
10 \\
\text { Total }\end{array}$ & $\begin{array}{c}13(50,0) \\
7(26,9) \\
4(15,5) \\
1(3,8) \\
1(3,8) \\
26(100) \\
\end{array}$ \\
\hline $\begin{array}{c}\text { Atividade de Ensino realizada envolvendo o tema } \\
0 \\
1 \\
2 \\
\text { Total } \\
\end{array}$ & $\begin{array}{l}16(61,5) \\
4(15,4) \\
6(23,1) \\
26(100)\end{array}$ \\
\hline TOTAL & $26(100)$ \\
\hline
\end{tabular}

Fonte: pesquisa de campo, 2018.

Os programas em que as teses e dissertações foram realizadas demonstram que a área das Ciências Sociais Aplicadas é a que realizou maior produção $(84,3 \%)$ dos trabalhos. Esse dado evidenciado vislumbra a importância de desenvolver pesquisas referentes à juventude rural nas diversas áreas do conhecimento. Quanto ao nível de estudo nesses Programas de Pós-Graduação, os autores produziram mais dissertações de mestrado $(88,5 \%)$ do que tese de doutorado $(11,5 \%)$, percebendo, assim, um espaço significativo para mais produções sobre as temáticas juventude, educação e ruralidade. (Verificar tabela 1) 


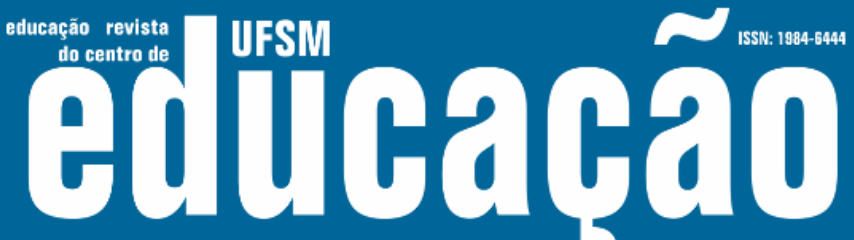 \\ 3}

ISSN: 1984-6444 | http://dx.doi.org/10.5902/1984644438667

curricular das disciplinas ofertadas nas Instituições de Ensino Superior. Por isso,

Em uma sociedade democrática é fundamental formar o professor na mudança e para a mudança por meio do desenvolvimento de capacidades reflexivas em grupo, e abrir caminho para uma verdadeira autonomia profissional compartilhada já que a profissão docente precisa 0 conhecimento como o contexto (IMBERNÓN, 2001, p.18)

$\mathrm{Na}$ verdade, com essa perspectiva, torna-se necessário um conhecimento que leva em consideração uma formação que traga no seu cerne a autonomia profissional para que o docente possa produzir conhecimentos dialogicamente articulado entre a teoria e prática, de forma a compartilhar em seus meios de interação social às transformações e necessidades de seus públicos. Portanto, ela necessita ser compreendida sob a ótica de sujeitos sociais localizados culturalmente, que carregam marcas dos contextos em que estão inseridos.

\section{Sentidos produzidos entre Juventudes Rurais e Educação nas teses e dissertações das Pós-graduações do Nordeste: atualidade e atualização}

Ao trazer para frente da discussão os elementos das teses e dissertações: tema, quadro teórico, metodologia e conclusão, verificou-se uma atualidade e atualização na compreensão das Juventudes Rurais. Para essa reflexão, iniciou-se com a análise da subcategoria "Tema", através do método da árvore de similitude (figura 1), proposto pelo Iramuteq e que se baseia na teoria dos grafos (MARCHAND \& RATINAUD, 2012). Nessa árvore, identificou-se, pelas coocorrências entre as palavras e seu resultado, os produtores de sentidos das pesquisas principalmente pelos termos juventude, rural e desenvolvimento. 


\section{Tusm 2

ISSN: 1984-6444 | http://dx.doi.org/10.5902/1984644438667

Figura 1 - Árvore de similitude da categoria "Tema" das teses e dissertações

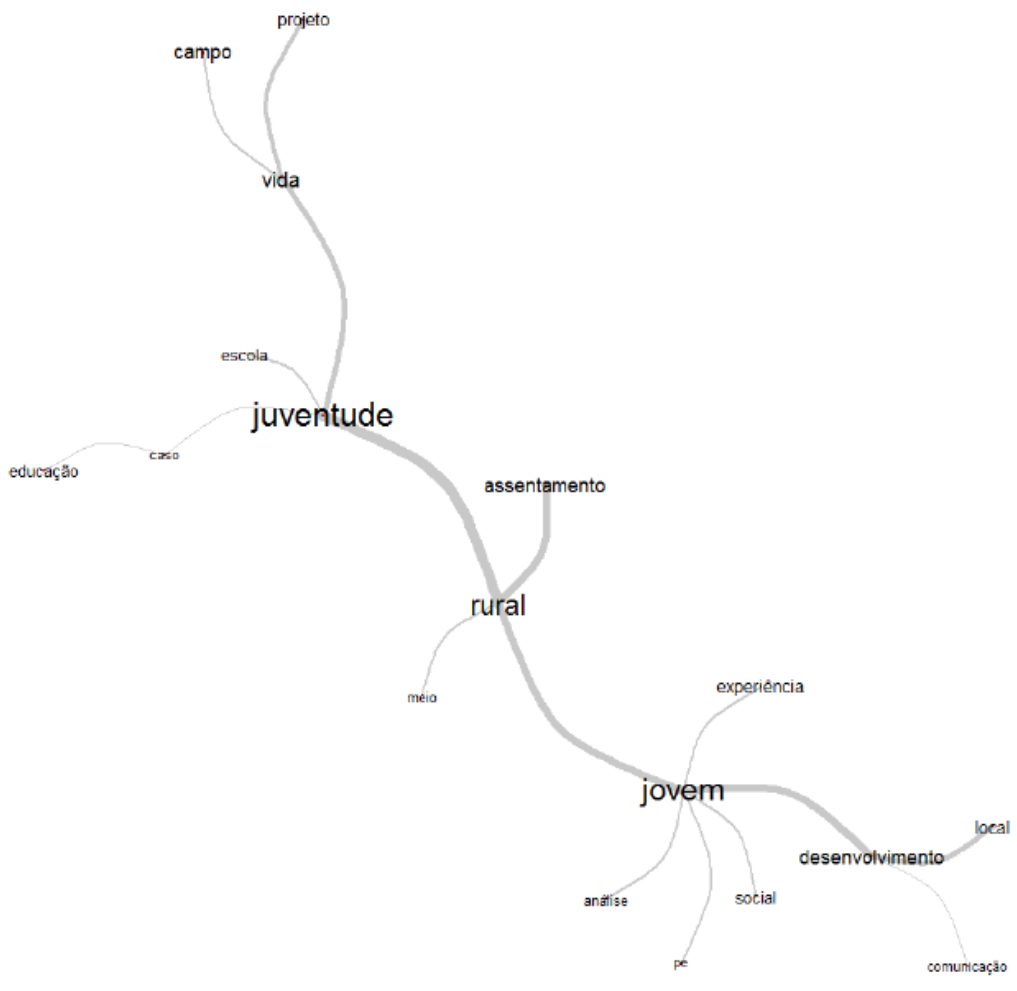

Fonte: Pesquisa de campo, 2018.

Especificamente, é possível perceber na arvore da figura 1 que os termos juventude, rural e desenvolvimento salientam que essas teses e dissertações buscam compreender as trajetórias dos jovens rurais e suas estratégias para desenvolver-se através da educação, pois os mesmos almejam melhores condições de vida para si, para sua família e para os lugares onde vivem, e a melhor forma de fazer isso acontecer, segundo essas teses e dissertações, é participando dos diversos projetos educativos que o poder público e os setores da sociedade civil organizada disponibilizam para eles.

No entanto, essas metas, muitas vezes, não são alcançadas por esses jovens porque, mesmo que eles gostem dos projetos realizados, não são envolvidos em outras ações que contribuam, de forma conectada, para o desenvolvimento local. Nesse sentido, a tese de Isabela Gonçalves Menezes, 2016, "No sertão da minha 


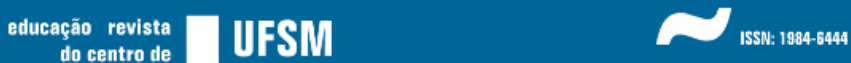

ISSN: 1984-6444 | http://dx.doi.org/10.5902/1984644438667

terra, o sentido da escolarização, as expectativas profissionais e o discurso sobre identidade e individualizações de jovens rurais estudantes do ensino médio em escolas urbanas", argumenta que:

\begin{abstract}
Uma das perspectivas dos jovens é a ida à escola com o objetivo de um futuro promissor por meio de um emprego e da autonomia financeira. Se o jovem atravessa uma fase da infância para a maturidade quando quer se afirmar e ter independência financeira; o do meio rural do sertão sergipano vive em um território que passa por transformações e tem priorizado projetos pessoais em contraposição à perpetuação da herança paterna. Todavia, tais escolhas não significam que desgostam do meio rural ou queiram se afastar dos familiares (MENEZES, 2016, p.28)
\end{abstract}

Apesar de muitos jovens buscarem uma saída pela educação (MENEZES, 2016), a dissertação de Priscila Teixeira da Silva "O olhar da escola sobre a juventude do campo na comunidade de Mutãs - Bahia: linhas que se cruzam, tessituras a se fazer", 2015, argumenta que para muitos desses jovens ainda prevalece a ideia de que a escola e a educação não são para eles, ou quando persistem nos estudos da escola urbana, acabam abandonando sua identidade camponesa.

As reflexões trazidas pelos temas estudados nas teses e dissertações remetem a uma atualidade dos referenciais teóricos já consolidados nos estudos sobre juventudes rurais. Com base nas informações mostradas pela nuvem de palavras da Figura 2, verifica-se que o corpus "Referencial teórico" das pesquisas tem na palavra Castro sua maior representação. Em termos numéricos, esta palavra vem a ser o núcleo da representação social sobre o corpus, e tem o sentido de ligação para o corpus dos textos. 


\section{تilloapão}

ISSN: 1984-6444 | http://dx.doi.org/10.5902/1984644438667

Figura 2 - Nuvem de palavras da categoria "Referencial teórico" das teses e dissertações

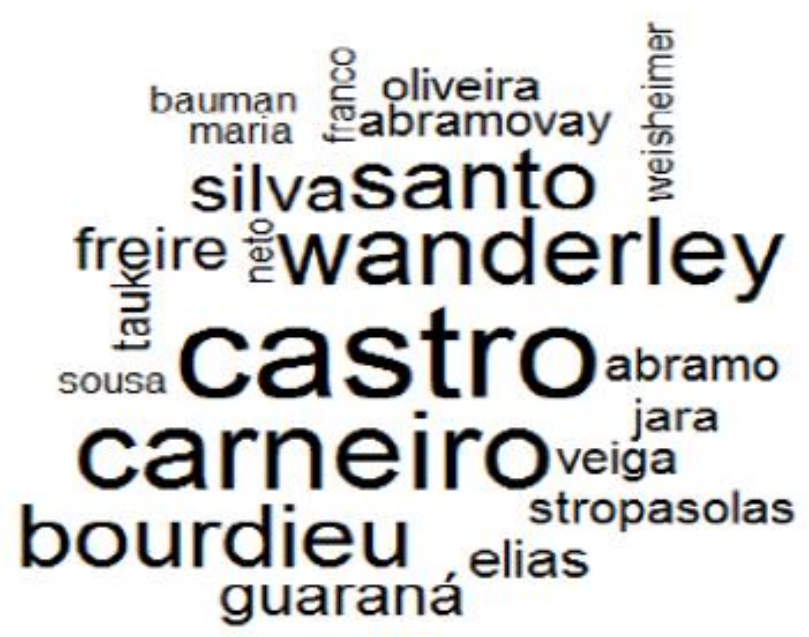

Fonte: pesquisa de campo, 2018.

Além de Castro, é possível observar que os autores com maior frequência nas dissertações e teses foram: Carneiro, Bourdieu e Wanderley. A nuvem de palavras mostra, de forma geral, que essas autoras desenvolveram seus temas voltados para pesquisas sobre juventudes rurais que envolviam de alguma forma experiências educacionais. Para citar, destaca-se "Os jovens estão indo embora?: Juventude rural e a construção de um ator político", produzido em 2009, por Castro. "A juventude é apenas uma palavra". In: Questões de Sociologia, de 1983, por Bourdieu. "O ideal rurbano: campo e cidade no imaginário de jovens rurais", de 1999, Carneiro. E "O mundo rural como espaço de vida: reflexões sobre a propriedade da terra, agricultura familiar e ruralidade", lançado em 2009, por Wanderley.

Essas referências trazem no bojo de suas reflexões sentidos de sociologias do "mundo rural" e da juventude em que suas tradições teóricas ultrapassam às clássicas, desde as chamadas de funcionalista ou de marxista clássica estruturalista. Nos referenciais dessas teses e dissertações, verificam-se preocupações com as mudanças que estão ocorrendo no mundo rural e da juventude brasileira. 


\section{Uism

ISSN: 1984-6444 | http://dx.doi.org/10.5902/1984644438667

Além disso, é importante situar que esse quadro da discussão teórica está articulado na interação com os caminhos metodológicos das teses e dissertações. Percebeu-se sua importância no fazer científico, pois revelou uma sintonia com as diretrizes gerais do método que orientou a pesquisa, os procedimentos utilizados na coleta de informações e nas suas análises.

Figura 3 - Árvore de similitude da categoria "Metodologia" das teses e dissertações

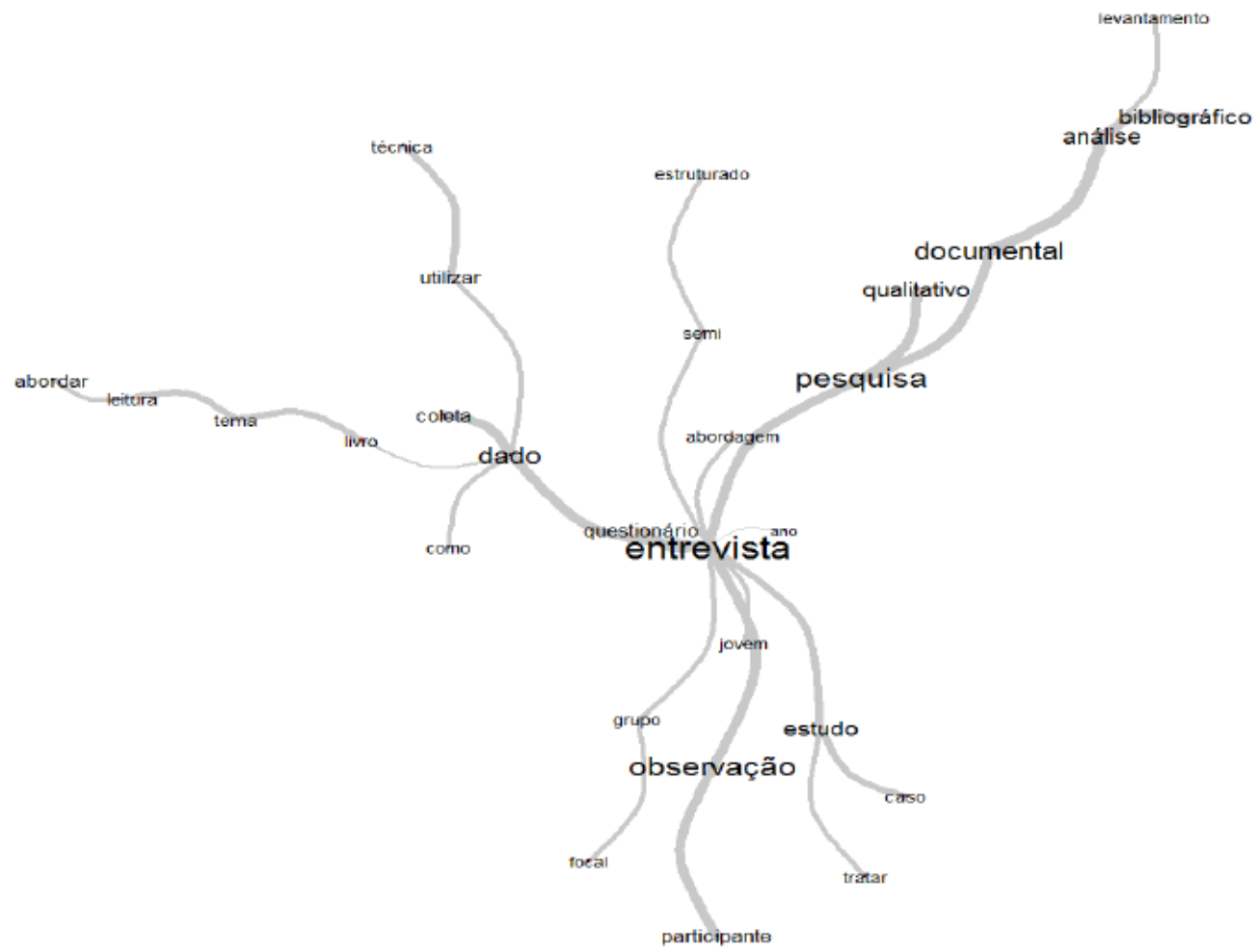

Fonte: Pesquisa de campo, 2018.

Ao tratar os textos metodológicos das teses e dissertações, através da árvore de similitude (ver figura 3), observou-se que a abordagem qualitativa, entrevistas, observação participante, grupo focal e análise documental são as mais utilizadas como os caminhos metodológicos de todo material analisado. Foi por meio delas que se chegaram às conclusões dos casos analisados. 


\section{Autharẫ}

ISSN: 1984-6444 | http://dx.doi.org/10.5902/1984644438667

No tema "Conclusão", utilizou-se para sua análise o Método de Reinert, a qual encontrou significância estatística, com significância de $76.47 \%$. O corpus geral do texto foi dividido em sete classes, para se obter um melhor aproveitamento das informações.

Essas classes são resultantes da Classificação Hierárquica Descendente, que se refere a uma classificação das palavras em ordem decrescente. De acordo com Reinert (1987), este método faz sucessivas divisões de texto em seguimentos. Esta função extraiu as classes de enunciados (conforme quadro 1) que são representativos, apresentando os resultados em forma de dendograma (conforme figura 4), isto é, em diagrama de árvore.

Quadro 1 - Núcleos temáticos das classes do dendograma "Conclusão"

\begin{tabular}{|c|l|}
\hline $\begin{array}{c}\text { CLASSES } \\
\text { DENDOGRAMA } \\
\text { CONCLUSÃO }\end{array}$ & \multicolumn{1}{c|}{ NÚCLEOS TEMÁTICOS } \\
\hline Classe 1 & $\begin{array}{l}\text { As atividades agrícolas tradicionais se distanciam das perspectivas juvenis pelo } \\
\text { ensino formal urbano }\end{array}$ \\
\hline Classe 2 & O jovem rural quer ter uma nova identidade e permanecer no campo \\
\hline Classe 3 & Transformações das identidades juvenis no rural brasileiro \\
\hline Classe 4 & A não efetividade das políticas públicas para o desenvolvimento rural sustentável \\
\hline Classe 5 & Os jovens buscam melhores oportunidades, mas permanecendo no campo \\
\hline Classe 6 & Não existe uma relação direta entre Politicas públicas e a educação do campo \\
\hline Classe 7 & $\begin{array}{l}\text { A juventude rural forma laços em seu meio que possibilitam ganhos individuais, } \\
\text { mas produzem outros sentidos para ficar ou sair do campo }\end{array}$ \\
\hline
\end{tabular}

Fonte: Pesquisa de campo, 2018.

A classe um, representada em vermelho da figura 4, e tendo como palavraschave agrícola, atividade e urbano, aborda a questão da educação e estudos dos jovens no meio rural. Em relação aos 26 trabalhos pesquisados, esta classe mostra a sua significância, pois aborda as (não)relações entre atividades agrícolas, educação, juventude no meio rural, seus valores e sonhos. 


\section{usm \\ $\sim$

Figura 4 - Dendograma da Classificação Hierárquica Descente da categoria

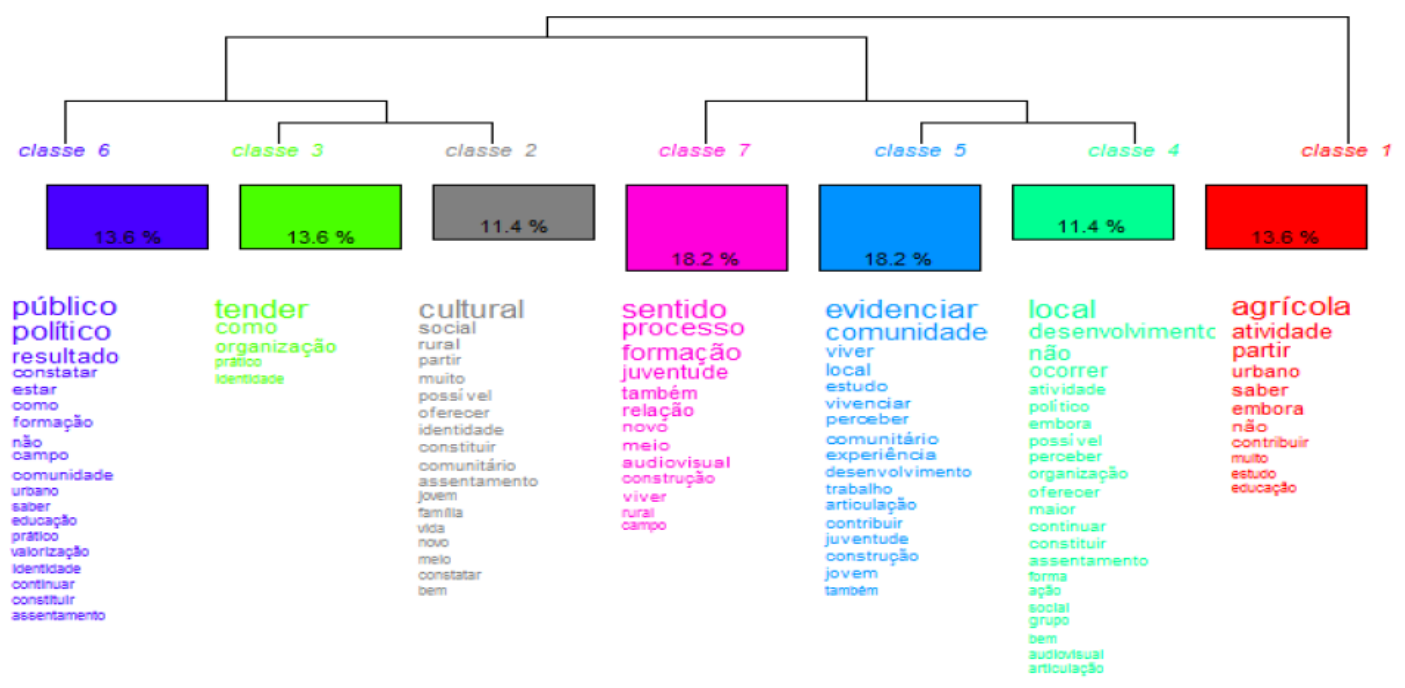

Fonte: Pesquisa de campo, 2018.

Para compreender as conexões de sentido das palavras-chave desta classe, buscou-se dialogar com trechos das teses e dissertações. Na dissertação de Virzangela Paula Sandy Mendes (2011), intitulada "Os projetos de vida da juventude do perímetro Curu-Paraipaba: entre o sonho e a realidade", a autora resgata o (não)lugar dos projetos de vida dos jovens rurais:

Embora dispersos, os desejos expressados pelos jovens denotam que eles podem contribuir para assegurar a sustentabilidade da área irrigada, desde que, a partir de ações coordenadas, os jovens não executem apenas atividades eminentemente agrícolas, mas também atividades não agrícolas que os possibilite dar vazão às suas capacidades criativa e empreendedora, ultrapassando a letargia política dos que receberam a dádiva e partiram para a gratidão. A democracia requer nova cidadania. Percebe-se que os jovens têm potencial para fazer suas escolhas e traçar seus próprios caminhos. (MENDES, 2011, p.8)

Pode-se perceber que esses jovens pretendem permanecer no seu perímetro, executando as atividades disponíveis e sonhando com um futuro melhor. Querem ter um emprego, uma profissão e, sobretudo, poder realizá-los no seu espaço rural. Não querem depender somente das atividades agrícolas tradicionais aos quais seus pais se construíram, mas empregos com direitos trabalhistas. Eles querem traçar seu próprio caminho. 


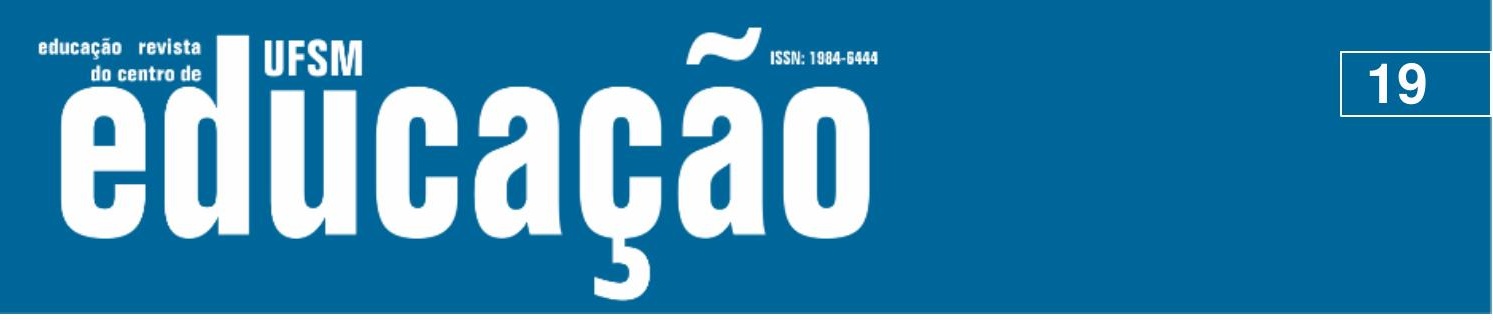

ISSN: 1984-6444 | http://dx.doi.org/10.5902/1984644438667

A classe dois (representada pela cor cinza, da figura 4), que tem como palavras-chave cultural, social e rural, aborda sobre o jovem rural ter uma nova identidade e permanecer em seu assentamento. A autora, Aurea Régia Oliveira da Silva, na dissertação intitulada "Participação e visibilidade dos jovens nos assentamentos rurais do município de Mari (PB)" observa que:

Os assentamentos rurais de Mari, apesar de suas limitações, oferecem condições de atração e de permanência de muitos jovens, já que tem uma infraestrutura razoável, com a presença de escolas, postos de saúde e até lanchonete. Além disso, um deles conta com a presença do Projeto Ponto de Cultura, que estimula os jovens a participarem de diversas atividades culturais e envolve-os nas atividades relativas a comunidade em geral. (SILVA, 2013, p.170)

Os jovens rurais consideram a escola importante para seu futuro e pretendem exercer profissões com estudo. Eles vislumbram conseguir exercer uma atividade em que possam conciliar com a vida no assentamento, eles têm preferência em continuar vivendo nos assentamentos rurais de Mari. Em outro trabalho, da dissertação de Talita Silva Bezerra (2013), "Vidas em trânsito: Juventude rural e mobilidade(s) pelo acesso do ensino superior", pode-se compreender que:

$\mathrm{Na}$ efemeridade dos acontecimentos a realidade está se modificando, e com ela, os indivíduos. Estamos sempre acrescentando algo novo ao nosso conhecimento de acordo com o que acontece ao nosso redor. Sair diariamente do município de origem e ir de encontro a um outro bem diferente, com outras pessoas de realidades distintas e semelhantes, com diversidade de outros modos de ser e agir, traz para os jovens de Araquém mudanças significativas. Ao mesmo tempo, eles reafirmam o que eles são e de onde vieram, o que forja uma construção dos mesmos como pessoas e como estudantes, trazendo novas responsabilidades consigo e com os demais, construindo identidades coletivas e individuais. (BEZERRA, 2013, p.133)

O fluxo entre o rural e o urbano por meio do ensino superior mostrou, no estudo de Bezerra (2013), que sair de seu lugar, conhecer novos ambientes e trocar experiências fazem com que os jovens rurais reflitam sobre as identidades coletivas e individuais, produzindo para si e seu lugar uma afirmação identitária mais complexa. Nesse caso, o cotidiano desses jovens está em comunicação permanente entre o rural e o urbano, tanto pela mobilidade material, quanto pela mobilidade virtual ou simbólica. De acordo com Carneiro (1999), a partir dessas relações com dois mundos, novas identidades entram em elaboração. 


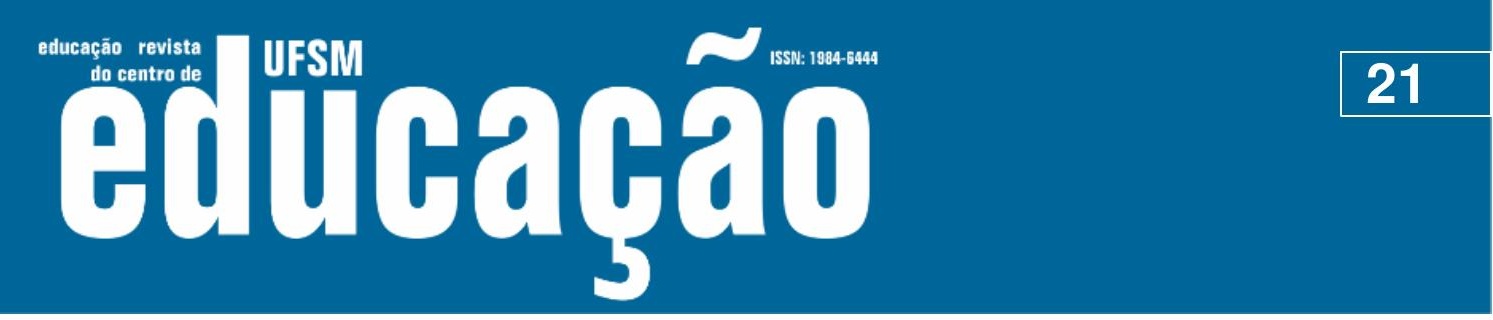

ISSN: 1984-6444 | http://dx.doi.org/10.5902/1984644438667

realizados pelas politicas públicas, e se empenhem bastante, suas ações locais não são resultantes desses projetos, principalmente porque não conseguem gerar renda exercendo as atividades apreendidas no âmbito da formação. Sobre esse respeito, a dissertação de Everaldo Costa Santana, com título “Juventude, Tecnologias da Comunicação e Desenvolvimento Local: análise da recepção da proposta do Grupo de Informática, Comunicação e Ação Local por Jovens do Meio Rural", destaca que:

De acordo com os objetivos do projeto, a ideia é que depois de formados os jovens continuem atuando na produção de vídeos, através da criação de produtoras de vídeos, prestem serviços em assessoria de comunicação para instituições locais e com isso possam gerar sua própria renda. Mas, a maioria dos jovens que produzem vídeos encontra dificuldades para ter acesso ao emprego nessa área. Mesmo assim, eles "buscam um emprego, que não precisa ser necessariamente na área de comunicação" (SANTANA, 2013, p. 7).

Observa-se, nesse sentido, a importância da implementação desses projetos para o desenvolvimento local. No entanto, ocorre uma invisibilidade desses jovens porque, embora o Estado ofereça programas e políticas voltadas para inclusão digital, o caminho percorrido entre estas até as necessidades locais se perde por não se enxergar a necessidade de políticas pós-formação. Isso é abordado na dissertação da Aline de Oliveira Bomfim, "Política Pública para Inclusão Digital de Jovens de Cachoeira Seca - Caruaru/PE”, 2016. Essa autora pondera que:

Dessa forma, com ajuda das TIC e TDIC, como ferramentas para o exercício de comunicação e informação, os jovens poderão empoderar-se e protagonizar contribuindo na fomentação de debates sobre direito, cidadania, inclusão digital e social e políticas públicas, promovendo, assim, a construção de sujeitos sociais capazes de se situar e atuar de forma contundente em seus espaços de vida. (BOMFIM, 2016, p. 15).

Desse modo, pode-se observar nas dissertações de Santana (2013) e Bonfim (2016) que as políticas públicas de inclusão digital e social se mostram necessárias para o desenvolvimento local pelas dimensões sociocultural e espacial, mas com necessidade de pensar ações pós-formação.

Analisando a classe cinco (representada pela cor azul espesso, da figura 4), tendo como palavras-chave evidenciar, comunidade e local, pode-se observar que se trata de jovens do campo escolarizados, sujeitos de uma política pública, que se apresentam sob mecanismos de qualificação e inserção para o mercado de trabalho. 


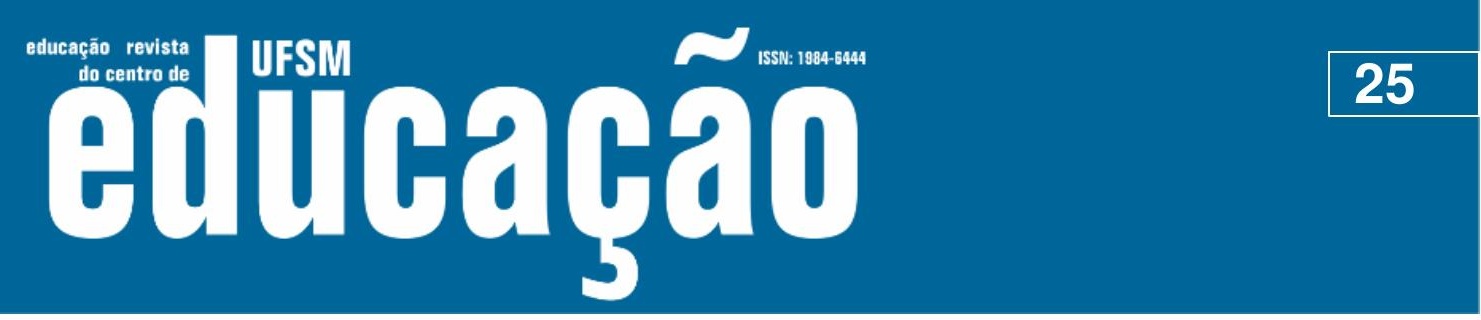

ISSN: 1984-6444 | http://dx.doi.org/10.5902/1984644438667

com o tema, principalmente durante o percurso do mestrado e/ ou doutorado, enveredando depois em novos campos de estudos e pesquisas. Por outro lado, verificou-se também uma continuidade e desdobramento dessa temática ao longo de sua carreira, através de produções ligadas à pesquisa acadêmica e/ ou às atividades de ensino e extensão ligadas às Instituições de Ensino Superior.

Identificou-se nos autores e suas produções uma diversidade de estratos, no que diz respeito a este campo de pesquisa. Cada trabalho analisado possui identidade própria e especificidades que o transforma em algo singular, mas também sob linhas mestras que possibilitam situar teórico-metodologicamente, desde correntes mais estrutural-funcionalistas às fenomenológicas e pós-estruturalistas, isto dentro de um grau de maturidade que pode ser visto como uma área em atualidade e atualização.

Nesse processo de atualidade e atualização das abordagens sobre a superação das problemáticas abordadas nas teses e dissertações, foi possível observar que grande parte dos trabalhos analisados abordam as identidades das juventudes rurais sob suas necessidades propostas com a educação e políticas públicas. No entanto, para que essa interação ocorra é necessário o fortalecimento no fazer pedagógico e na formação continuada dos profissionais voltadas para a educação do campo, bem como a implementação de políticas públicas na direção da valorização dos profissionais, da melhoria da infraestrutura educacional e desenvolvimento rural sustentável.

A investigação permitiu concluir que os estudos referentes à pesquisa sobre o levantamento da produção do conhecimento de dissertações e teses, no período de 2007-2016, sobre Juventude rural e educação nos programas de Pós-graduação do Nordeste do Brasil vêm crescendo. O propósito até aqui não foi esgotar este debate, mas forjar possibilidades para futuros trabalhos. Ainda que não explicitamente, é possível perceber nesses estudos uma busca por um reconhecimento e demarcação da área, uma delimitação de quem são, a que vieram, como chegaram e para onde vão.

Portanto, observou-se a procedência autoral dos trabalhos acadêmicos, com discussões que têm trazido novos caminhos para a produção dos Programas de 


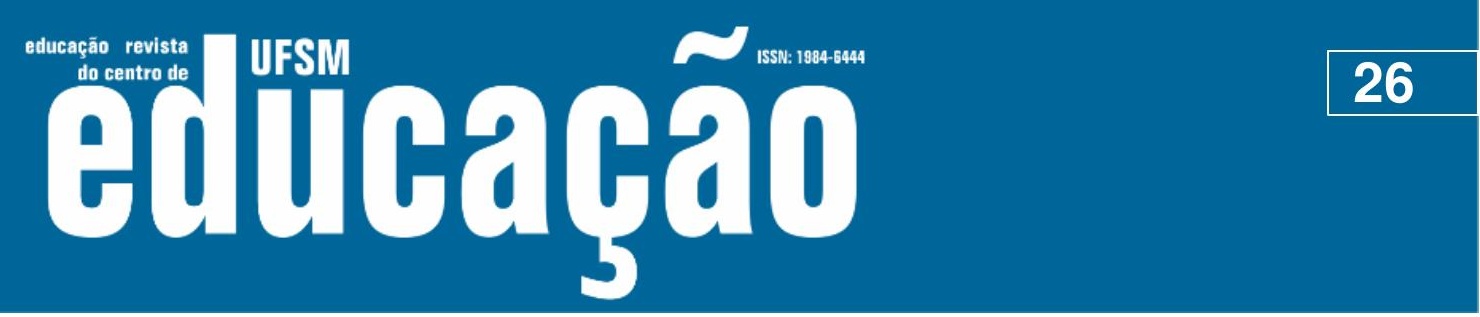

ISSN: 1984-6444 | http://dx.doi.org/10.5902/1984644438667

Pós-Graduação, possibilitando repensar os campos de conhecimentos sobre juventudes rurais e educação pelas áreas de Ciências Humanas e Sociais Aplicadas.

\section{Referências}

ABRAMOVAY, Ricardo et al. Juventude e Agricultura Familiar: desafio dos novos padrões sucessórios. Brasília: edições Unesco, 1998.

ABREU, Maria Evilene de Sousa. Processos artísticos e comunicacionais da juventude no meio rural: modos de cartografar e intervir no assentamento Barra do Leme.141p. Dissertação (Mestrado em Comunicação), Instituto de Cultura e Arte, Universidade federal do Ceará. Fortaleza. 2015.

ALVES, José Willame Felipe. O Processo de Educação no Assentamento Rural Vida Nova Transval, no Município de Canindé. 61p. Dissertação (Mestrado em políticas Públicas e Sociedade), Centro de Estudos Sociais Aplicados, Universidade Estadual do Ceará. Fortaleza. 2012.

BARDIN, Laurence. Análise de conteúdo. Lisboa: Ed 70. 1977.

BEZERRA, Talita Silva. Vidas em trânsito: juventude rural e mobilidade(s) pelo acesso ao ensino superior.142p. Dissertação (Mestrado em Sociologia), Centro de Ciências Humanas, Universidade Federal do Ceará. Fortaleza. 2013.

BOMFIM, Aline de Oliveira. Política pública para inclusão digital de jovens de Cachoeira Seca, Caruaru, PE. 115p. Dissertação (Mestrado) - Universidade Federal Rural de Pernambuco, Programa de Pós-Graduação em Extensão Rural e Desenvolvimento Local, Recife, 2016.

BRANDÃO, Zaia; BAETA, Anna Maria Bianchini; ROCHA, Any Dutra Coelho. Evasão e repetência no Brasil: a escola em questão. 2. ed. Rio de Janeiro, RJ: Dois Pontos, 1986.

BRITO, Jaqueline Andrade. Vivências e experiências em educação e trabalho: um estudo de caso sobre jovens do campo egressos do curso técnico profissionalizante em agropecuária /pronatec ubaíra-ba (2012-2014). 133p. Dissertação (Mestrado em Educação do Campo), Centro de Formação de Professores, Universidade federal do recôncavo da Bahia. Amargosa. 2016.

BRUMER, Anita. A problemática dos jovens rurais na pós-modernidade. In: CARNEIRO, Maria José; CASTRO, Elisa Guaraná (Ed.). Juventude rural em perspectiva. Rio de Janeiro: Mauad X, 2007. p. 35-51.

BOURDIEU, Pierre. O poder simbólico. Rio de Janeiro: Ática, 1989. 


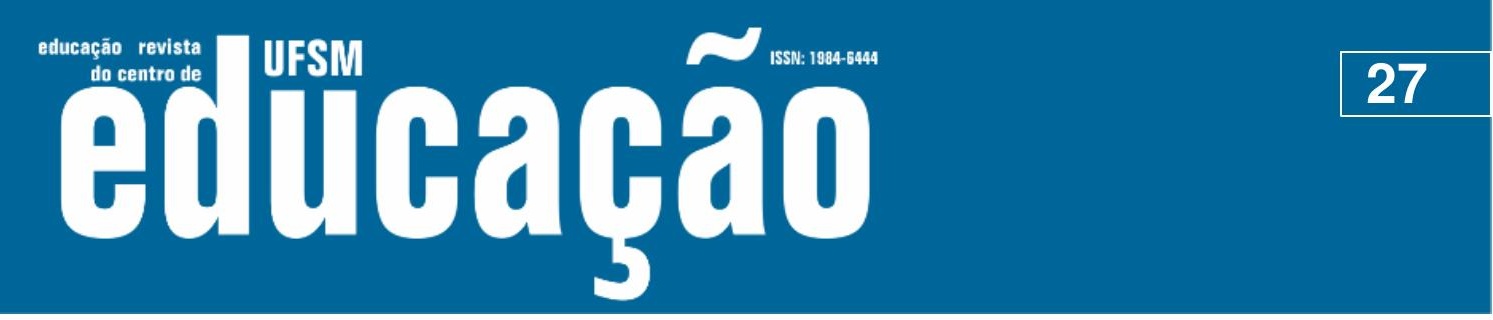

ISSN: 1984-6444 | http://dx.doi.org/10.5902/1984644438667

BOURDIEU, Pierre. Questões de sociologia. Rio de Janeiro: Marco Zero. 1983.

CAMARGO, Brigido Vizeu; JUSTOS, Ana Maria. iramuteq: Um software gratuito para análise de dados textuais. Florianópolis, 2013. Disponível em: http://pepsic.bvsalud.org/scielo.php?script=sci_arttext\&pid=S1413-

389X2013000200016. Acesso em: 20 de junho de 2019.

CAMPELLO, Bernadete Santos. Encontros científicos. In: CAMPELLO, Bernadete Santos; CENDÒN, Beatriz Valadares; KREMER, Jeannette Marguerite (Org). Fontes de informação para pesquisadores e profissionais. Belo Horizonte: Ed. UFMG, 2000.

CARNEIRO, Maria José; CASTRO, Elisa Guaraná de. Juventude rural em perspectiva. Rio de Janeiro: Mauad X, 2007.

CARNEIRO, Maria José. O ideal urbano: campo e cidade no imaginário de jovens rurais. In: TEIXEIRA DA SILVA, Francisco Carlos et al. (Org.). Mundo rural e política. Rio de Janeiro: Campus, 1999.

CASTRO, Elisa Guaraná de Castro et al.. Os jovens estão indo embora? In: Juventude rural e a construção de um ator político. Rio de Janeiro: MAUAD X; Seropédica, RJ: EDUR, 2009

DICIONÁRIO DE CIÊNCIAS SOCIAIS. Juventude. Rio de janeiro: FGV, 2ª ed., 1987.

FERRARI, Dilvan Luiz et al. Dilemas e estratégias dos jovens rurais: ficar ou partir. Revista estudos Sociedade e Agricultura. Vol. 12, n. 2, Outubro de 2004, p.237269.

IMBERNÓN, Francisco. Formação docente e profissional: formar-se para a mudança e a incerteza. São Paulo: Cortez, 2001.

LACERDA, Aureliana Lopes de, et al.. A importância dos eventos científicos na formação acadêmica: estudantes de biblioteconomia. Revista ACB: Biblioteconomia em Santa Catarina, Florianópolis, v.13, n.1, p.130-144, jan./jun., 2008. Disponível em: https://revistaacb.emnuvens.com.br/racb/article/view/553. Acesso em 27 de jul de 2020.

LETA, Jacqueline. As mulheres na ciência brasileira: crescimento, contrastes e um perfil de sucesso. Estud. av., São Paulo, v. 17, n. 49, p. 271-284, Dez. 2003. Disponível em: http://www.scielo.br/scielo.php?script=sci_arttext\&pid=S0103$40142003000300016 \&$ lng=en\&nrm=iso. Acesso em: 21 jun de 2019.

LUDKE, Menga; ANDRÉ, Marli E. D. A. Pesquisa em educação: abordagens qualitativas. São Paulo: EPU, 1986. 


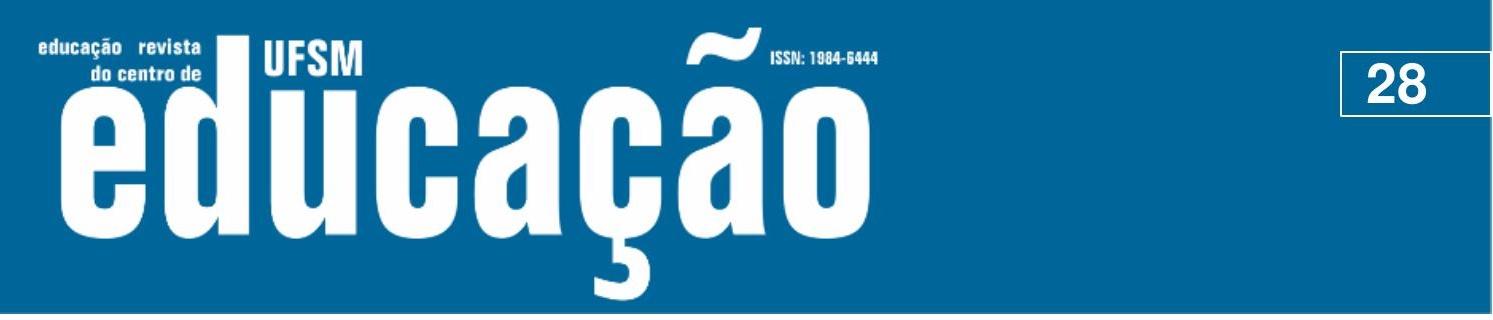

ISSN: 1984-6444 | http://dx.doi.org/10.5902/1984644438667

MARIN, Joel Orlando Bevilaqua. Conformismo e resistência dos camponeses à extensão rural. 1991. 253p. Dissertação (Mestrado em Extensão Rural), Universidade Federal de Santa Maria, Santa Maria, 1991.

MARCHAND, Pascal ; RATINAUD, Pierre. L'analyse de similitude appliqueé aux corpus textueles: les primaires socialistes por l'election présidentielle française. Actes des 11eme Journées internationales d'Analyse statistique des Données Textuelles. JADT 2012 (pp. 687-699). Liège, Belgique. Retrieved April 13, $2013 . \quad$ Disponível em: http://lexicometrica.univparis3.fr/jadt/jadt2012/Communications/Marchand,\%20Pascal\%20et\%20al.\%20-

$\% 20 \mathrm{~L} \% 27$ analyse $\% 20 \mathrm{de} \% 20$ similitude\%20appliquee\%20aux\%20corpus\%20textuels .pdf. Acesso em 21 de jun 2019.

MARIN, Joel Orlando Bevilaqua. Juventude rural: una invencióndel capitalismo industrial. Estudios Sociológicos, México. Cuatrimestral, v. 27, n. 80, p. 2, 2009.

MENEZES, Isabela Gonçalves. No sertão da minha terra, o sentido da escolarização, as expectativas profissionais e o discurso sobre identidade e individualizações de jovens rurais estudantes do ensino médio em escolas urbanas. 361p. Tese (Doutourado em Educação), Universidade Feral de Sergipe. São Cristovão. 2016

MENDES, Virzângela Paula Sandy. Os projetos de vida da juventude do perímetro Curu-Paraipaba: entre o sonho e a realidade: entre o sonho e a realidade.175p. Dissertação (Mestrado em políticas Públicas e Sociedade), Centro de Estudos Sociais Aplicados, Universidade Estadual do Ceará. Fortaleza. 2011.

QUAPPER, Klaudio Duarte. Juventude o juventudes? Acerca de como mirar y remirar a lãs juventudes de nuestro continente. In: Burak, S. (Org.), Adolescência y juventud em América Latina. Costa Rica: Libro Universitário Regional. 2001, pp. 57-76.

REINERT, Max. Une méthode de classification descendante hiérarchique: application à l"analyse lexicale par contexte. Les cahiers de l'analyse des données, v. 8, n. 2, 1987.

SANTANA, Everaldo Costa. Juventude, Tecnologias da Comunicação e Desenvolvimento Local: análise da recepção da proposta do Grupo de Informática, Comunicação e Ação Local por Jovens do Meio Rural. 135p. (Dissertação) Programa de Pós-Graduação em Extensão Rural e Desenvolvimento Local: UFRPE, Recife, 2013.

SCHNEIDER, Sergio. A pluriatividade na agricultura familiar. 2. ed. - Porto Alegre: Editora da UFRGS, 2009a.

SCHNEIDER, Sergio. Ciências Sociais, Ruralidade e Territórios: em busca de novas referências para pensar o desenvolvimento. Campo.Território, v. 4, p. 24--62, 2009b. 
